\title{
EL CAMINO HACIA UNA POLÍTICA DE PROMOCIÓN CULTURAL EN EL JAPÓN CONTEMPORÁNEO Y LOS INICIOS DE UNA CAMPAÑA DE FORTALECIMIENTO DE LA IDENTIDAD NACIONAL
}

\author{
YUNUEN YSELA MANDUJANO SALAZAR \\ Universidad de Guadalajara
}

"Japón está inventando de nuevo a la superpotencia", ${ }^{1}$ escribió Douglas McGray, en 2002, en su artículo sobre lo que llamó el cool japonés. Hablaba acerca de la creciente presencia cultural de Japón en el extranjero y el potencial que tal circunstancia tenía de convertirse en la llave para que el país se recuperara de su largo periodo de recesión económica. En la academia comenzó rápidamente a discutirse el asunto desde muy diversos ángulos. Numerosos autores se han enfocado desde entonces en el análisis de la expansión de la cultura popular nipona en el continente asiático, así como en la influencia económica y política del país en dicha región, lo cual es visto por algunos como un intento de Japón por borrar la mala impresión que todavía persiste entre muchos asiáticos debido a su época imperialista. Por otro lado, algunos más lo ven no como un alejamiento de tales esfuerzos colonialistas, sino como una nueva forma de conquista japonesa que ha levantado sospechas. ${ }^{2}$

Este artículo fue recibido por la dirección de la revista el 31 de julio de 2013 y aceptado para su publicación el 29 de abril de 2014.

${ }^{1}$ Douglas McGray, “Japan’s Gross National Cool”, Foreign Policy, núm. 130, 2002, p. 44. La mayoría de los materiales analizados y referidos están escritos en los idiomas inglés y japonés; todas las citas textuales de dichas fuentes corresponden a traducciones realizadas por la autora.

${ }^{2}$ Véase Leo Ching, "Imaginings in the Empires of the Sun: Japanese Mass Culture in Asia”, Boundary 2, vol. 21, núm. 1, 1994, pp. 198-219; B. H. Chua y Koichi Iwabuchi (comps.), East Asian Pop Culture: Analyzing the Korean Wave, Hong Kong, Hong Kong University Press, 2008; Peng Er Lam, “Japan's Quest for 'Soft Power': Attraction and Limitation”, East Asia, vol. 24, núm. 4, 2007, pp. 349-363, y Reiko 
En el presente escrito he decidido, por el contrario, enfocarme no en el efecto de la cultura japonesa en el extranjero, sino en el contexto nacional enfrentado por Japón en la primera década del siglo xxI, el cual dio lugar a una política concreta para la promoción de la cultura nacional, en un primer momento dirigida hacia el extranjero y con objetivos claramente económicos; así como en las circunstancias que impulsaron, a partir del año 2011, la evolución de esa política para incluir también metas de diplomacia y de fortalecimiento de la identidad nacional.

\section{Cool Japan, una política para vender cultura}

“Algunas veces comenzamos a conocernos a nosotros mismos, más que por nuestros propios esfuerzos, por las acciones de otros", ${ }^{3}$ inicia un reporte del Departamento de Investigación Económica de la Organización de Comercio Exterior de Japón (Japan External Trade Organization, JETRO) refiriéndose a los postulados de McGray. El artículo antes mencionado había captado la atención de amplios sectores de expertos en Estados Unidos, Europa y Japón, y había dado pie a que reconocieran una situación que algunos académicos y periodistas japoneses ya habían notado: la popularidad que algunos productos de la cultura pop japonesa estaban teniendo entre consumidores de diferentes partes del mundo. ${ }^{4}$ Desde luego, la plataforma donde el artículo de McGray fue presentado (la revista estadounidense de política y economía internacional Foreign Policy) y la idea del Gross National Cool (un juego de palabras con el término en

\footnotetext{
Ogawa, "Re-imagining the Relationship between Japan and Korea: Popular Culture and Civic Engagement", en Henk Vinken, Yuko Nishimura, Brian White y M. Deguchi (coords.), Civil Engagement in Contemporary Japan. Established and Emerging Repertoires, Nueva York, Springer, 2010, pp. 189-202. Dichos autores presentan diferentes puntos de vista en el debate sobre los aspectos positivos y negativos de la presencia de los productos culturales japoneses en otros países asiáticos como una forma explotada por Japón para redefinir su imagen ante sus vecinos.

${ }^{3}$ Japan External Trade Organization, “Cool”Japan's Economy Warms Up, Tokio, JETRO, 2005, p. 1.

${ }^{4}$ Koichi Iwabuchi, Recentering Globalization. Popular Culture and Japanese Transnationalism, Londres, Duke University Press, 2002.
} 
inglés para el producto nacional bruto) habían llegado a darle un nombre al fenómeno: Cool Japan.

Seguramente, el principal argumento detrás de la exposición de McGray era que se podía esperar que Japón hiciera uso del soft power derivado de la popularidad de su cultura para servir a sus objetivos, tanto económicos como políticos; sin embargo, los esfuerzos japoneses estuvieron enfocados con especial interés en el primer campo por un largo tiempo. Los sectores público y privado apuntaban a los beneficios que una mayor promoción de la producción cultural nacional fuera de su territorio podían significar para apoyar la revitalización de la economía. No es de extrañar la limitada visión en un principio, pues la idea llegaba en un momento en el que el producto interno bruto había caído a su nivel más bajo desde que había estallado la "burbuja" financiera, a inicios de la década de 1990. ${ }^{5}$ Por tal razón, la primera serie de planes en torno de la promoción cultural tuvieron un enfoque meramente económico y se concentraron en la industria de contenidos, donde la mayoría de los productos del fenómeno observado por McGray tenían su origen.

En el año 2003, el Ministerio de Economía, Comercio e Industria (Ministry of Economy, Trade and Industry, METI) ${ }^{6} \mathrm{pu}-$ blicó un reporte titulado "Hacia la internacionalización de la industria de contenidos. Enviar la marca Japón al mundo", 7 en el cual era presentada la situación de la industria y se discutía una propuesta para promover su internacionalización. Los burócratas identificaron que la expansión de los contenidos japoneses en el extranjero podía mejorar la imagen del país o añadir valor a la marca Japón, es decir, al nombre del país como productor, y así tener efectos económicos positivos en otras industrias. Tras revisar las estrategias que Estados Unidos, Inglaterra, Alemania, Corea del Sur y Taiwan estaban utilizando para su propia internacionalización cultural, los funcionarios

${ }^{5}$ Cabinet Office Government of Japan, "Monthly Economic Report (December 2002)”, en página web de Cabinet Office, datos al 31 de diciembre de 2002.

${ }^{6}$ Keizai Sangyōshō en japonés.

${ }^{7}$ Keizai Sangyōshō, "Kontentsu Sangyō no kokusai tenkai ni mukete. Sekai he hasshin, Nippon burando”, en página web de Keizai Sangyōshō, sección Seisaku, julio de 2003. 
del METI hicieron un llamado a darle la debida importancia a los productos de cultura popular en las políticas públicas. En el reporte se lee: "los contenidos nacionales [...] han sido vistos domésticamente con indiferencia como industria, puesto que son percibidos como algo para niños o para juego". ${ }^{8}$ Así, la sugerencia al gobierno era que se involucrara activamente no sólo proveyendo recursos para la promoción de los contenidos nacionales en el extranjero, sino también tomando medidas para regular el comercio internacional y proteger los productos japoneses de la piratería, uno de los mayores problemas en mercados como el de China.

Durante el siguiente año, el METi dio un paso más y preparó un seminario con gente relacionada con los principales campos de la industria para discutir las formas de capitalizar la popularidad de los contenidos japoneses, particularmente en Asia, así como la forma de involucrar a otras industrias. Se estableció que la estrategia debía centrarse en los productos que ya eran suficientemente reconocidos en el extranjero: anime (animación japonesa), manga (historietas japonesas), videojuegos, J-pop (música popular japonesa), películas y series televisivas. Eran éstos los productos clave del fenómeno Cool Japan: el anime representaba más de $60 \%$ de la programación de dibujos animados en el mundo; el manga era conocido y buscado por cada vez más sectores de consumidores en Asia, Estados Unidos y varios países europeos, lo que generaba importantes flujos de dinero derivados de licencias para la traducción y la publicación de títulos en dichos mercados; los productos de hardware y software de videojuegos japoneses dominaban el mercado mundial, $\mathrm{y}$ personajes, películas, programas de televisión, música y moda, ya tenían tiempo de ser altamente consumidos en los mercados del este asiático. Debido a ello, la industria de contenidos estaba produciendo un valor de cerca del doble de lo que generaba la industria del acero, lo que repercutía positivamente en otros sectores de la economía, como la agricultura, la cual comenzó a recibir una creciente demanda de frutas, vegetales, arroz y té, principalmente del este de Asia, donde los costosos productos japoneses se habían convertido en una marca y su consumo,

${ }^{8}$ Ibid., p. 21. 
en un símbolo de estatus en la región que estaba viviendo un auge económico. ${ }^{9}$

En 2004, en su reporte anual sobre la industria de contenidos, el METI informó que las estrategias dinámicas que la República de Corea imprimía para la promoción de sus productos culturales en Asia estaban poniendo en riesgo el dominio que Japón tenía hasta ese momento. ${ }^{10} \mathrm{La}$ ola coreana, ${ }^{11}$ el equivalente del Cool Japan, fue el nombre que se le dio al fenómeno de elevada popularidad de los productos culturales surcoreanos en otros países.

La República de Corea había visto un cambio de régimen político a fines de la década de 1980. En 1988, luego de años de censura en los medios de comunicación, comenzó un proceso de liberalización que permitió la llegada de contenidos y otros productos culturales extranjeros. Ello había puesto a los medios de comunicación coreanos en peligro: su industria fílmica había perdido la mayoría del mercado local ante los productos de Hollywood y la programación televisiva era cada vez más extranjera que nacional. En 1994, el gobierno coreano notó las repercusiones, positivas y negativas, que las industrias culturales podían tener para su economía, por lo que estableció el Buró de la Industria Cultural bajo el Ministerio de Cultura y Deporte. Unos años después, mientras sufría la crisis financiera asiática de 1997, la cultura popular coreana fue promovida como parte de las industrias de exportación destinadas a reconstruir la economía nacional.

En 1999, el presidente Kim Dae Jung, quien se hizo llamar “presidente de la cultura”, estableció la Ley Básica para la Promoción de la Industria Cultural, la cual destinaba 1.15\% del presupuesto gubernamental para tales efectos. ${ }^{12}$ Todos estos esfuerzos estaban dando resultados en su mercado doméstico

9 Japan External Trade Organization, “Cool” Japan's Economy Warms Up, op. cit., pp. 2-10; Keizai Sangyōshō, "Kontentsu Sangyō", op. cit., pp. 6-14.

${ }^{10}$ Keizai Sangyōshō, "Kore made Waga Kuni Kontentsu Sangyō no Kokusai tenkai ni muketa torigumi”, en página web de Keizai Sangyōshō, sección Bunka Shingikai, 21 de julio de 2004.

${ }^{11}$ Llamada también hallyu según la pronunciación coreana, y hanryū o kanryū en el idioma japonés.

${ }^{12}$ Doobo Shim, "Hybridity and the Rise of Korean Popular Culture in Asia", Media, Culture E Society, vol. 28, núm. 1, 2005, pp. 25-44. 
-la gente consumía nuevamente los productos culturales coreanos-y, más lentamente, en el continente, donde los mercados de habla china eran los principales receptores en ese momento. ${ }^{13}$

Sin embargo, para 2003, la incipiente ola coreana llegó a Japón e impulsada por el éxito encontrado ahí habría de tomar fuerza. El producto cultural que abrió el mercado nipón fue la serie televisiva Sonata de invierno, la cual alcanzó ratings de audiencia equivalentes a aquellos que tenían los programas domésticos de horario estelar; un producto evidentemente coreano, en el sentido de estar completamente producido con insumos de Corea (historia, locaciones, actores, etcétera), fue acogido principalmente por un sector de mujeres de mediana edad. De acuerdo con algunos estudios sobre el fenómeno que significó este drama televisivo en Japón, las consumidoras fueron profundamente influidas por la serie, la cual despertó su interés en la cultura coreana o, al menos, en la cultura que era representada en esa historia. ${ }^{14}$

Además de dicha serie y su audiencia concentrada entre mujeres adultas, una cantante adolescente de origen coreano, BoA, ya había comenzado a abrir otro sector al imponer un récord en la industria musical japonesa por ser la primera artista internacional en lograr vender más de un millón de copias de un álbum en $2002 .{ }^{15}$ Ella fue también la primera en ser presentada con una estrategia que años después habría de transformar la ola coreana en un tsunami en Japón. BoA atrajo a japoneses jóvenes, pero, contrario a Sonata de invierno, no representaba algo indiscutiblemente coreano; de hecho, la clave de su éxito en Japón pudo deberse a que fue promovida por una de las más grandes empresas disqueras nacionales, Avex, y a que tanto sus canciones como su interacción con los medios de comunicación y fans de ese país eran en el idioma japonés. Incluso, para el

${ }^{13}$ Seiko Yasumoto, "Japan and Korea as a Source of Media Cultural Capital”, en Duk-Soo Park (ed.), Global Korea: Old and New: Proceedings of the Sixth Biennial Conference Korean Studies Association of Australasia, Sidney, The Korean Studies Association of Australia, 2009, pp. 311-321.

${ }^{14}$ Ogawa, "Re-imagining the Relationship...", op. cit., pp. 189-202; Yasumoto, "Japan and Korea...", op. cit., pp. 311-321.

${ }^{15}$ Recording Industry Association of Japan, "Nendo betsu Mirion Serā Ichiran”, página web de Recording Industry Association of Japan, sección Kakurui Sōkei, 31 de diciembre de 2002. 
año 2005, cuando Oricon -la empresa encargada de recabar las estadísticas de la industria de la música y el entretenimiento en Japón- reportó el segundo álbum de ventas millonarias de BoA, no hubo mención de ella como parte de la ola coreana. ${ }^{16}$

Luego de cuatro años desde que los productos culturales coreanos llegaran a Japón y estuvieran conquistando mercado doméstico, el METI publicó su reporte final sobre la estrategia global de contenidos. En el prefacio del documento, los colaboradores - un grupo de estudio integrado por gente de la industria-solicitaban acciones para evitar que, en el futuro cercano, la totalidad de la industria de contenidos japonesa fuera devorada por Estados Unidos y Europa. El principal problema que veían era no sólo que las exportaciones de productos culturales nacionales apenas mostraran crecimiento en los últimos años, sino también que la demanda doméstica estaba disminuyendo. Fueron precisos al expresar su preocupación; incluso conscientes de que la industria de contenidos tenía las facetas complementarias de cultura y negocios, estaban "enfocados solamente en el lado de los 'negocios', y consideraban cómo la 'cultura' [podía] ser utilizada para crear 'valor económico'”. ${ }^{17}$

Los líderes de la industria de contenidos presentaron un análisis del contexto mundial, donde indicaban la prominencia de las estrategias estadounidenses y europeas, pero fueron particularmente cuidadosos al notar las amenazas más cercanas: el proyecto nacional de la República de Corea para expandir su industria de contenidos hacia Asia y las políticas de censura y cuotas de China que dificultaban ese mercado a los productos japoneses. El reporte expresa una preocupación por el estado de crisis que la industria nacional vivía y la pérdida de ventajas en el mercado global; se proponía una iniciativa para enfocar la política de promoción de contenidos japoneses en la región asiática. Al presentar las estrategias clave para incursionar en los diferentes mercados de la zona, se destacaba la importancia de producir versiones de los contenidos en las lenguas locales de cada uno de ellos; ésa había sido la táctica utilizada por

${ }^{16}$ Oricon Style, "BoA, Besto-han ga 100 man mai wo toppa", página web de Oricon Style, sección News, 24 de mayo de 2005.

${ }^{17}$ Ministry of Economy, Trade and Industry, Contents Global Strategy. Final Report, Tokio, METI, julio de 2007, p. 1. 
los cantantes coreanos en su intento por conquistar el mercado japonés, pero era algo que la mayoría de los artistas japoneses no harían.

Para el año 2009, la ola coreana estaba en todo Japón reforzada por el fenómeno Tohoshinki, un grupo musical coreano del tipo idol, ${ }^{18}$ integrado por cinco hombres jóvenes que estaban siendo promocionados de la misma forma que BoA, a través de actividades dedicadas específicamente al mercado japonés y dirigidas por una filial de Avex. El grupo había debutado en Japón en 2005, momento a partir del cual se concentró en dos mercados principales, su nativa Corea y Japón, aunque realizaba actividades también en otros países asiáticos. Entre 2005 y finales de 2007, Tohoshinki había ido haciéndose de una base de seguidores japoneses creciente, aunque aún no tan notable como la de los grupos idol locales; sin embargo, en 2008 llegó a los titulares japoneses por haber alcanzado una serie de récords de ventas. ${ }^{19} \mathrm{~A}$ diferencia de Sonata de invierno o BoA, quien había prácticamente desaparecido de Japón para dedicarse a otros mercados, Tohoshinki estaba atrayendo a seguidores de más amplios rangos de edad, aunque mayoritariamente mujeres.

BoA, Tohoshinki y otros artistas coreanos que comenzarían a invadir los medios de comunicación japoneses a partir de 2009 - para entonces ya bajo la etiqueta de ola coreanahabían llegado apoyados por la política de promoción cultural del gobierno coreano. Sus agencias promotoras en la República de Corea seleccionaban y formaban grupos de adolescentes, los presentaban al público coreano y de otras partes de Asia y, luego, ya con cierto éxito en esos mercados, establecían contactos con agencias y disqueras japonesas -o bien creaban una

${ }^{18}$ Los grupos idol en Japón tienen como características principales ser multifacéticos; realizan una amplia variedad de actividades en medios de comunicación, y representan tipos ideales de género. Véase Yunuen Ysela Mandujano Salazar, "El mercado de idol varones en Japón (1999-2008): caracterización de la oferta a través del estudio de un caso representativo", tesis de maestría en Estudios de Asia y África, El Colegio de México, México, 2009.

${ }^{19}$ Cuatro sencillos lanzados en 2008 fueron primer lugar de ventas semanales con un promedio de 60000 copias, no comparables a los más exitosos cantantes japoneses de ese momento que estaban vendiendo alrededor de 300000 en el mismo periodo, pero significaban un récord para un grupo extranjero y mostraban que estaba consistentemente ganando terreno. Véase Oricon Style, "Nenkan CD Arubamu rankingu", página web de Oricon Style, sección Ranking, 31 de diciembre de 2008. 
filial con promotores japoneses- para atacar el mercado nipón al estilo local. Ello estaba dando resultados cuando, en 2009, la separación de los integrantes de Tohoshinki por un conflicto con su agencia corean $\mathrm{a}^{20}$ causó furor entre los seguidores japoneses del grupo, y convirtió la ola coreana en un tsunami: las marcas de cosméticos coreanas aparecieron en los mayores centros comerciales, el barrio coreano en Tokio, Shin Okubo, se convirtió en un lugar de moda para los japoneses, donde se podía encontrar desde ingredientes de comida coreana hasta carteles de los ídolos de la ola; pero, sobre todo, el turismo de Japón a la República de Corea se vio grandemente incrementado como efecto directo de esta tendencia cultural.

De acuerdo con las estadísticas de la Organización de Turismo de Corea, tomando como muestra el primer mes de cada año, en enero de 2003, antes de que las mujeres japonesas descubrieran Sonata de invierno, las visitantes japonesas eran sólo $41 \%$ de los 153703 japoneses que entraron a Corea del Sur. Para enero de 2008, después del fenómeno del drama televisivo coreano y el comienzo del fenómeno de Tohoshinki, los porcentajes de hombres y mujeres estaban casi parejos, donde las mujeres representaban $47 \%$ del total de visitantes japoneses; sin embargo, un año después, en enero de 2009, cuando Tohoshinki ya competía en popularidad con los ídolos japoneses, las visitantes niponas a Corea representaron casi 59\%, y mantuvieron la mayoría porcentual frente a los varones los siguientes años e incrementaron el total de visitantes japoneses -en la muestra mensual-a un promedio de 200000 personas en $2013 .{ }^{21}$

Era claro que las políticas que el gobierno coreano desarrollaba para exportar sus contenidos nacionales y promover su cultura estaban teniendo resultados satisfactorios. Tal como años antes se hablaba del fenómeno del Cool Japan, en 2009 era la ola coreana la que llegaba a los encabezados de las noticias internacionales. Joseph Nye, quien había acuñado el término

${ }^{20}$ Oricon Style, "Eibekkusu, Tohoshinki no Nippon de no Katsudō Shien wo aratamete happyō", página web de Oricon Style, sección News, 6 de agosto de 2009. Oricon Style, "Tohoshinki, Katsudō Kyūshi happyō", página web de Oricon Style, sección News, 4 de abril de 2010.

${ }^{21}$ Véase Korea Tourism Organization, "Korea, Monthly Statistics on Tourism", en página web de Korea Tourism Organization, 2013. 
de soft power, escribía: "La cultura popular coreana ha cruzado fronteras, particularmente entre la gente joven de los países vecinos de Asia [...] Como resultado, Corea del Sur está comenzando a diseñar una política externa que le permitirá jugar un papel más importante en las instituciones internacionales". 22 Luego, The Economist reportaba: "Las exportaciones de videojuegos coreanos, dramas de televisión y música popular (Kpop) se han duplicado desde 1999 [...] En términos de cuota de mercado, estos números aún son modestos contra la industria de historietas japonesas [...] pero las ventas de manga japonés han caído desde que alcanzaron su pico en 1995 ". ${ }^{23}$

El gobierno japonés lo sabía. Estaban perdiendo internacionalmente y, lo peor, domésticamente había problemas también. ${ }^{24}$ En el mercado de la música, los artistas nacionales tenían que enfrentar la competencia que significó la llegada de numerosos artistas coreanos bajo la etiqueta de la ola coreana. Había quienes creían que la industria japonesa de la música y el entretenimiento se estaba quedando relegada en cuanto a las tendencias de mercado y, por lo tanto, arriesgaba perder totalmente su posición. ${ }^{25}$

Finalmente, en junio de 2010, el METi estableció la Oficina de Promoción de las Industrias Culturales bajo el nombre de Oficina Cool Japan, que estaría a cargo de diseñar y aplicar planes y medidas para promover dichas industrias como un sector estratégico, y facilitar su expansión tanto fuera como dentro de Japón. ${ }^{26}$ Con el establecimiento de la Oficina, el término Cool Japan se expandió para referirse no sólo a los productos originalmente asociados a la industria de contenidos, sino también a un amplio rango de lo que se llamó "industrias creativas", que incluían la industria de contenidos además de otros produc-

${ }^{22}$ Joseph S. Nye, “South Korea’s Growing Soft Power”, The Korea Times, 11 de noviembre de 2009.

${ }^{23}$ Reuters, "South Korea's Pop-cultural exports Hallyu, yeah! A 'Korean wave' washes Warmly over Asia", The Economist, 25 de enero de 2010.

${ }^{24}$ Ministry of Economy, Trade and Industry, Report on the Content Industry's Growth Strategy, Tokio, METI, mayo de 2010.

${ }^{25}$ Robert M. Poole, "Only got 4Minutes to take the World. Girls make 'Candy Funk’ Korea's New Export”, The Japan Times Beta, 30 de abril de 2010.

${ }^{26}$ Keizai Sangyōshō, "Cool Japan Shitsu no Setchi ni tsuite", Web Archiving Project, 8 de junio de 2010. 
tos y servicios como arquitectura, servicios computacionales, muebles, artesanías, joyería, alimentos y la misma industria del turismo. Con esta visión "holística", las industrias creativas japonesas se volvían más importantes para la economía nacional en términos de ventas y de gente empleada, que la industria automovilística y la industria de electrónicos de consumo. ${ }^{27}$

\section{Cool Japan, una fuente de soft power}

Luego de perder su momento de auge económico, en la década de 1990, el gobierno japonés tenía problemas para encontrar la forma de hacer crecer al país. Al mismo tiempo, la rápida industrialización de sus vecinos había sido, por un lado, una amenaza para la posición de Japón en la región y, por otro, una oportunidad para expandir sus mercados. En 2010, el Gabinete lanzó una nueva estrategia de crecimiento en la cual se establecía la importancia del mercado asiático y el flujo de gente, bienes y dinero de la región para alimentar "el poder de la marca 'Japón' y la fuerza diplomática”. ${ }^{28}$ Identificaba como elementos clave para la conquista de capitales extranjeros: las industrias creativas niponas, la promoción del país como nación orientada al turismo y el desarrollo de recursos humanos hábiles en campos como el deporte y la cultura.

Las compañías japonesas difícilmente podrían crecer si no encontraban demanda extranjera para sus productos y servicios; sin embargo, ninguna estrategia funcionaría a menos que Japón pudiera ser atractivo en el exterior en ámbitos diversos. En el área diplomática, el gobierno japonés debía ser capaz de negociar en otros países asiáticos la llegada de compañías y productos nipones, así como las condiciones que les permitieran obtener beneficios de esa incursión en mercados extranjeros; $y$, evidentemente, los productos y los servicios japoneses debían atraer a la gente de esos países para que los consumieran. Para tales efectos, el soft power era crucial.

${ }^{27}$ Ministry of Economy, Trade and Industry, Cool Japan Strategy, Tokio, METI, enero de 2012.

${ }^{28}$ Ministry of Economy, Trade and Industry, The New Growth Strategy Blueprint for Revitalizing Japan, Tokio, METI Cabinet Decision, 18 de junio de 2010, p. 28. 
La noción de soft power, de Joseph Nye, corresponde al cuerpo teórico de la política, la diplomacia y las relaciones internacionales; denota la habilidad de manejar las preferencias de otros y persuadir positivamente por medio de la atracción. Más que simple influencia, la cual puede ser obtenida también por el hard power (medios militares y económicos), el softpower utiliza activos intangibles, como la personalidad, la cultura o los valores, para atraer a la gente e inducirla a seguir al líder que posee tal poder, es decir, no es coercitivo; en el caso de las naciones, el soft power deriva de la cultura, las políticas y los ideales políticos que ese país representa en el exterior. ${ }^{29}$

Refiriéndose al soft power en el mundo, Nye había reconocido a Japón como el país con más recursos latentes en Asia. También había identificado que ello se debía en gran medida a la atracción cultural, a través de expresiones tanto contemporáneas como tradicionales, que le habían ganado seguidores en el resto del mundo. No obstante, también apuntaba una limitante: el pasado militar japonés. ${ }^{30}$ Efectivamente, de acuerdo con una encuesta, realizada en 2008 por The Chicago Council on Global Affairs, alrededor de 60\% de los chinos, los surcoreanos y los indonesios percibían a Japón como una potencial amenaza militar. ${ }^{31}$ Incluso, lejos del terreno de las armas, la presencia de los contenidos y los productos culturales de Japón en otros países asiáticos había sido criticada por algunos como una fachada de sus intenciones imperialistas. ${ }^{32}$

Luego del régimen colonialista que varios países asiáticos vivieron a manos de Japón durante la primera mitad del siglo Xx, éste había tenido constantes fricciones con sus vecinos y era visto con resentimiento por algunos. Una de las principales críticas hacia el gobierno ha sido su rechazo a ofrecer disculpas por las atrocidades que Japón causó durante ese periodo. En la pri-

${ }^{29}$ Joseph S. Nye, Soft Power: The Means to Success in World Politics, Nueva York, Public Affairs, 2004; Joseph S. Nye, The Benefits of Soft Power, Cambridge, Harvard Business School, 8 de febrero de 2004.

${ }^{30}$ Joseph S. Nye, Soft Power, op. cit., pp. 86-87.

31 The Chicago Council on Global Affairs, Soft Power in Asia: Results of a 2008 Multinational Survey of Public Opinion, Chicago, The Chicago Council on Global Affairs, 2009, p. 8.

${ }_{32}$ Véase la discusión que hace al respecto Ching, "Imaginings in the Empires of the Sun”, op. cit., pp. 198-219. 
mera mitad de la década de 1990, el emperador Akihito y el primer ministro Murayama dieron algunos pasos en este sentido, al ofrecer disculpas medidas, ${ }^{33}$ pero los conflictos no han disminuido debido a que otras acciones del gobierno japonés han contradicho tales palabras: ministros que continúan visitando públicamente el Santuario de Yasukuni —donde son venerados algunos japoneses considerados criminales de guerra-, la publicación de libros de texto donde se minimizan las acciones de Japón en esa etapa de la historia y declaraciones poco afortunadas de oficiales japoneses. ${ }^{34}$

La República de Corea y China son los dos países vecinos que representan las situaciones más problemáticas para Japón. Políticamente existen continuas tensiones y desacuerdos, pero sigue existiendo una alta codependencia entre ellos; en la esfera económica son sus mayores rivales, pero también los dos más importantes mercados de la región; y en los ámbitos cultural y social sigue existiendo animosidad de ciertos sectores hacia todo lo japonés, pero también son los grupos étnicos de esos países los que constituyen las comunidades no japonesas más grandes que residen permanentemente en el país. Incluso cuando los diplomáticos japoneses han tratado de construir una identidad de nación pacífica que promueve la libertad y la democracia al relacionarse con el resto de Asia, ${ }^{35}$ difícilmente puede percibirse de tal forma cuando tantas situaciones problemáticas persisten. Por lo tanto, para que las metas económicas de los líderes japoneses se volvieran alcanzables, se necesitaba dedicar un considerable esfuerzo a crear una imagen del país que les permitiera aplicar las estrategias mayores.

De acuerdo con Nye, hay tres tácticas centrales en la diplomacia pública enfocadas a la creación de una imagen atractiva de un país (la fuente del soft power): comunicación diaria para mantener al público al tanto de las decisiones en cuanto a

${ }^{33}$ Idem. Véase también Yasumoto, "Japan and Korea...", op. cit., pp. 311-321.

${ }^{34}$ Véanse por ejemplo las recientes declaraciones del alcalde de Osaka, las cuales fueron cubiertas por la prensa internacional debido a ese contexto de tensión que vive Japón en las relaciones diplomáticas con el resto de Asia: Malcolm Foster, "Japanese Mayor: Wartime Sex Slaves were Necessary”, Yahoo! Newes, 14 de mayo de 2013.

${ }^{35}$ Hidetaka Yoshimatsu, "Identity, Policy Ideas, and Asian Diplomacy: Japan's Response to the Rise of China”, International Area Studies Revierw, vol. 15, núm. 4, 2012, pp. 359-376. 
política pública, la aplicación de estrategias de comunicación similares a las de las campañas publicitarias, y el desarrollo de relaciones con individuos clave en diversos campos, entre ellos el de la cultura. Es evidente que el éxito de esas tácticas depende mucho de un uso adecuado de los medios de comunicación, pero también de que sean altamente compatibles con la cultura popular. Una campaña de promoción abiertamente nacionalista probablemente no ayudaría a hacer más atractivo el país en otras naciones y, por el contrario, podría inspirar peligrosos sentimientos xenofóbicos en su propia sociedad. Por otro lado, si la campaña no aparece como evidentemente política ni ideológica, sino que es insertada en las imágenes y los discursos de los fenómenos de cultura popular que ya poseen una vasta reserva de poder de atracción entre la sociedad local e internacional, entonces la probabilidad de que el país consiga un mayor soft power se incrementa. La clave para esta estrategia de uso de la cultura popular es la cercana cooperación entre las élites económicas, gubernamentales, de medios de comunicación y de los productores culturales.

Éste había sido el proceso seguido por la República de Corea desde finales de la década de 1990; el gobierno coreano había estado trabajando muy de cerca con los productores culturales y las grandes corporaciones para promover las exportaciones culturales, el turismo y las marcas coreanas en Asia y, gradualmente, en otros mercados. Ello había originado la ola coreana y se estaban cosechando frutos: la imagen de "Corea del Sur" había conseguido diferenciarse en el mundo de la de "Corea del Norte"; la República de Corea estaba resultando atractiva para mucha gente joven a través de sus productos culturales y para los gobiernos de muchos países debido a sus vanguardistas productos tecnológicos, los cuales eran impulsados en el mercado global por los rostros de la ola coreana.

En 2010, este fenómeno estaba ganando cada vez más terreno en Japón e imponía una fuerte competencia a los productos culturales nacionales; en el resto de Asia y poco a poco en el resto del mundo, los productos de la ola coreana habían ido relegando a los del Cool Japan. El Servicio Coreano de Información y Cultura reportó, orgullosamente, en un panfleto sobre la ola coreana, que, para 2010, los videos musicales de artis- 
tas coreanos tenían las mayores audiencias no asiáticas en YouTube, pero que, además, la audiencia más grande para ellos era Japón. Incluso se declara una nueva ola coreana ese año, por la gran expansión que los productos de Corea estaban teniendo en toda Asia. ${ }^{36}$ La creciente atracción de la República de Corea en el mundo estaba siendo notada, pero también era conocido el papel activo del gobierno, como los apoyos económicos que daba a las compañías nacionales que promovían la cultura coreana en el extranjero. Esta agresiva campaña cultural fue pronto interpretada por algunos como una estrategia de nacionalismo "duro". 37

El gobierno japonés, por otro lado, seguiría una táctica más sutil. Tal como ha sido argumentado previamente, los burócratas japoneses habían estado analizando la situación por un largo tiempo. Al comienzo del año fiscal de 2010, incluso antes del establecimiento de la Oficina Cool Japan por el METI y de que se declarara oficialmente a la industria turística como parte de las industrias creativas, los medios de comunicación japoneses reportaron que la Agencia de Turismo de Japón (Japan Tourism Agency, JTA), que era parte del Ministerio de Tierra, Infraestructura, Transporte y Turismo (Ministry of Land, Infrastructure, Transport and Tourism, MLITT), había designado al grupo idol japonés Arashi como "representante para la promoción del turismo japonés”, un título bastante descriptivo para los embajadores de una campaña de turismo titulada Japan Endless Discovery.

El grupo era probablemente el más popular y exitoso acto artístico japonés en ese momento, tanto en Japón como en el este asiático. Esto fue abiertamente expresado por los representantes de la JTA como la razón para la elección de Arashi. ${ }^{38}$ Tanto las declaraciones oficiales como los reportes de los medios de comunicación expresaban la expectativa de que el grupo, en su papel de "rostro de Japón" y debido a la elevada atracción

${ }^{36}$ Korean Culture and Information Service, The Korean Wave: A New Pop Culture Phenomenon, Seúl, Ministry of Culture, Sports and Tourism, 2011, pp. 35-56.

${ }^{37}$ Véase los comentarios del profesor Choi en el artículo de Ulara Nakagawa, “Korea's Hallyu Boom?”, The Diplomat, 27 de octubre de 2010.

${ }^{38}$ Kankōchō, “Arashi x Kankōchō 'Kankō Rikoku Navigator' to shite Arashi wo kiyō”, en página web de Kankōchō, sección Hōdō Kaiken, 8 de abril de 2010. 
que ejercía dentro y fuera del país, ayudara a incrementar el flujo de visitantes a lugares turísticos. Asimismo, se especificaba que el grupo y su agencia promotora estaban contribuyendo gratuitamente a toda la campaña. ${ }^{39}$

Unos días después, la JTA anunciaba que uniría fuerzas con el Aeropuerto Internacional de Haneda, en Tokio, para promover el turismo doméstico. ${ }^{40}$ Para septiembre del mismo año, Japan Airlines, uno de los principales proveedores de vuelos domésticos en ese aeropuerto, comenzó a utilizar la música y la imagen del grupo Arashi en el avión que servía tres importantes destinos nacionales. Japan Airlines lanzó una declaración de prensa donde se dice que se eligió al grupo como imagen debido a que Arashi y la compañía tenían la misma intención de enviar un mensaje positivo desde Japón y, además, porque su popularidad era amplia y representaba al turismo japonés. ${ }^{41}$

Al mismo tiempo, la jTA publicó un libro de promoción cultural nacional y lo envió a todas las escuelas primarias, secundarias y preparatorias del país con el objetivo de inspirar entre los niños y los adolescentes japoneses el orgullo por su país y su identidad nacional, así como la revaloración de las diversas y más tradicionales culturas locales latentes dentro del país. ${ }^{42}$ El libro fue titulado El Arashi de Japón y era, desde luego, una producción que involucraba al grupo Arashi; los cinco miembros del grupo aparecen en el libro en diferentes locaciones y narran sus viajes haciendo énfasis en su grata sorpresa al "redescubrir” Japón:

Hemos contemplado la verdadera globalización; sin embargo, la mejor forma de acercarnos al mundo es avanzar teniendo en mente a Japón, a nuestro pueblo, a nuestra familia, a nosotros mismos. En estos momentos debemos estar verdaderamente orgullosos de ser japoneses. En Japón,

${ }^{39}$ Idem. Véase también Kankō Keizai Shimbun, "Hōnichi kankō PR ni Arashi kiyō”, en página web de Kankō Keizai Shimbun, sección Kankō gyōsei, 17 de abril de 2010.

${ }^{40}$ Kankōchō, "Kankō Promotion in Haneda Kūkō no Jisshidantaiga Kettei!", en página web de Kankōchō, sección Hōdō Kaiken, 22 de abril de 2010.

${ }^{41}$ Japan Airlines, “Tokubetsutosōki 'Jal Arashi JET' gashūkō”, comunicado de prensa en la página web de Japan Airlines, 9 de septiembre de 2010.

${ }^{42}$ Kankōchō, "Kankō Rikkoku Kyōiku ni shisuru tosho no sōfu to gakkō ni okeru sono katsuyō ni tsuite”, en página web de Kokudokōtsūshō, 1 de septiembre de 2010. 
donde vivimos, hay mucha gente que es amable y sincera. Viviendo en las grandes ciudades se vuelve difícil verlo, por lo cual nos embarcamos en un viaje para reencontrarnos con esa gente. ${ }^{43}$

Por otro lado, la campaña internacional Japan Endless Discovery comenzó a transmitir spots televisivos alrededor de Asia que mostraban a los miembros de Arashi hablando chino, coreano e inglés e invitando a la gente a disfrutar tanto los aspectos comúnmente relacionados con el Japón tradicional -aguas termales, la vista del monte Fuji, los templos budistas y santuarios sintoístas, el sushi- como aquellos relacionados con el Cool Japan.

El caso de Arashi permite seguir la sutil y bien coordinada cooperación entre el gobierno, las corporaciones, los medios de comunicación y los productores culturales japoneses para promover ciertos elementos relacionados con un discurso sobre la identidad nacional, una tendencia particularmente evidente desde el año 2010. Esta estrategia tenía dos caras: fuera del país se promovía la infraestructura, los productos y los servicios japoneses ya populares en el exterior, a través de un conjunto de ideas e imágenes convencionales; en contraste, la campaña interna, aparte de fortalecer la importancia de los símbolos japoneses convencionales, buscaba restablecer el interés y el orgullo domésticos en elementos culturales que pudieran ser relacionados con unas cualidades japonesas esenciales, poniendo el énfasis en la gente. Para las audiencias japonesas, Arashi estaba haciendo una contribución a su país al actuar "de buena voluntad" en la campaña de JTA; el discurso de sus integrantes como representantes del turismo era amable y sencillo, sin trazas de “imperialismo". Mientras tanto, la campaña con Japan Airlines era vista como una más entre los múltiples contratos que tenía el grupo para representar productos o servicios; el cruce discursivo entre ambas campañas era fácilmente asimilado como parte de la alta intertextualidad característica de los medios de comunicación japoneses.

${ }^{43}$ Arashi, Nippon no Arashi Pokettoban, Tokio, M.Co., 2011, p. 9. 


\section{E1 Japón tradicional para la nación y para el mundo}

A menos de un año desde el establecimiento de la Oficina Cool Japan, el gran terremoto del este de Japón golpeó al país, lo que presentó nuevos retos. El terremoto del 11 de marzo de 2011 había costado más de 15000 vidas humanas y causado un tsunami que había demolido viviendas y dañado una planta nuclear. ${ }^{44}$ Todo ello provocó otra serie de problemas que los japoneses tenían que enfrentar entre el golpe emocional de tener una parte de su país destruida. A pesar de que las reacciones alrededor del mundo eran de simpatía hacia los japoneses, también se temían los efectos económicos, ambientales y de salud que el desastre podía significar internacionalmente. Incluso dentro del país existía un temor hacia los efectos que la radiación podía tener en el agua y los productos agrícolas, lo cual podía afectar la demanda doméstica de los pocos cultivos que habían sobrevivido en la región noreste del país.

El Consejo de la Oficina Cool Japan, formado por miembros del sector privado, académicos, periodistas y representantes de diferentes ministerios, respondió rápidamente con un plan llamado significativamente "Crear un nuevo Japón uniendo 'cultura e industria' y a 'Japón y el mundo". En este plan hay un claro cambio en el enfoque: de la búsqueda de metas mayormente económicas a recomendaciones con un fuerte contenido ideológico. El Consejo notó el daño potencial que la incertidumbre que había dejado el terremoto podía causar, no sólo en la esfera económica, por lo que sugirieron medidas para reforzar el proyecto de la marca Japón:

La fortaleza y la profundidad espiritual del japonés al enfrentar estoicamente el desastre está siendo alabada por la gente alrededor del mundo. [...] Internamente, el terremoto ha revivido la "empatía y solidaridad" y el "espíritu de cooperación”, cualidades que tradicionalmente existían en la población japonesa. [...] Al mismo tiempo, el fuerte sentido de responsabilidad de los japoneses al cumplir con sus compromisos, el

${ }^{44}$ Ministry of Economy, Trade and Industry, Economic Impact of the Great East Japan Earthquake and Current Status of Recovery, Tokio, METI, 16 de mayo de 2011. National Police Agency of Japan, "Damage Situation and Police Countermeasures associated with 2011 Tohoku district off the Pacific Ocean Earthquake", datos al 11 de marzo de 2013, página web de National Police Agency of Japan. 
trabajo en equipo, la innovación y la capacidad para responder a los requerimientos del momento han permitido una rápida restauración de la cadena de provisión de bienes. Los gerentes y los empleados, a pesar de haber sido afectados por el desastre, continúan involucrados en sus negocios para no causar problemas a sus clientes. Sin duda, son estos aspectos comunes en la sociedad japonesa los que están en el corazón de la "marca Japón". Lo que se necesita en este momento son fuentes confiables de información que cubran desde el desastre hasta la restauración, acciones que promuevan la restauración de las regiones afectadas y la revitalización de Japón, y vías para restaurar el brillo de la "marca Japón". [...] Todos los ministerios gubernamentales necesitarán trabajar juntos para desarrollar medidas relevantes hacia esos fines. [...] Deben devolver a los japoneses el espíritu esencial que tradicionalmente poseían, al tiempo que se logra una nueva "evolución". ${ }^{45}$

\section{Los miembros del consejo percibieron las necesidades y las} oportunidades que la situación presentaba para transferir el eje de la marca Japón y el proyecto de promoción cultural de la "superficialidad" de lo cool a la "profundidad" de las cualidades que, desde la aparición del discurso de nacionalismo cultural nibonjinron, habían sido atribuidas a la identidad nacional japonesa. ${ }^{46}$

${ }^{45}$ Cool Japan Advisory Council, Creating a New Japan. Tying together 'Culture and Industry' and 'Japan and the World', Tokio, Cool Japan Advisory Council, 12 de mayo de 2011, p. 1.

${ }^{46}$ El nibonjinron tuvo su apogeo en las décadas de 1970 y 1980 cuando defendió, bajo las premisas básicas de una homogeneidad universal entre los japoneses y la equivalencia entre raza, cultura, lengua y tierra, unas características únicas de la sociedad japonesa que se consideraban la razón detrás de su exitosa recuperación luego de la devastación sufrida en la Segunda Guerra Mundial. En este discurso, la sociedad japonesa es caracterizada por estar orientada al grupo, poner un alto valor a las jerarquías verticales y promover actitudes de dependencia entre los estratos de esa jerarquía. Centrales al modelo de identidad nacional del nihonjinron estaban la figura y los valores del salary man, el hombre de oficina que trabajaba arduamente y dedicaba incuestionablemente tiempo y energía a las necesidades de su empresa y, por extensión, de su nación. Este movimiento se propagó a través de literatura de consumo masivo, instalándose como un género literario en sí mismo y llevando las ideas de académicos, cuasi académicos y periodistas, al público en general que leía ávidamente sobre las teorías de lo que hacía especiales a los japoneses frente al resto del mundo. Sin embargo, para finales de la década de 1980, en medio de una economía de burbuja, la popularidad de estos contenidos disminuyó, al mismo tiempo que la sociedad mostraba características cada vez más distantes a las de ese modelo de identidad japonesa. Para un análisis sobre el nihonjinron, véase Harumi Befu, Hegemony of Homogeneity. An Anthropological Analysis of Nihonjinron, Melbourne, Trans Pacific Press, 2001; Yumiko Iida, Rethinking Identity in Modern Japan: Nationalism as Aesthetics, Londres, Routledge, 2002; Kosaku Yoshino, Cultural Nationalism in Contemporary Japan: A Sociological Enquiry, Londres, Routledge, 2005. 
Desde la naturaleza sincrética de los japoneses hasta su particular sentido estético, la sugerencia fue reforzar la identidad de los japoneses y entonces mostrarla al mundo para apoyar la ya admirada faceta innovadora y posmoderna de su cultura.

El terremoto llegó a dar un nuevo enfoque al proyecto de la promoción cultural del país, el cual era, hasta ese momento, relativamente nuevo y segmentado. Por un lado, estaba el METI con su Oficina Cool Japan concentrándose en la promoción de las industrias creativas en el extranjero por el potencial económico que ello podía tener en la producción nacional; incluso siendo la cultura el principal producto de esas industrias y habiendo sido la cultura popular la que había comenzado a ser atractiva a los mercados extranjeros, la cultura en sí misma no había sido vista como un elemento tan importante como los negocios que ella podía acarrear. Por otro lado, estaba el MLITT con una fuerte campaña dirigida a la expansión del turismo nacional, la cual se centraba en una reivindicación cultural; en ella se estaba poniendo por delante el poder de atracción que producciones exitosas de la cultura popular ejercían en potenciales turistas nacionales y foráneos a través de dos discursos distintos, aunque complementarios: uno amigable y receptivo hacia los extranjeros, y otro dedicado a inspirar un orgullo nacional "blando", esto es, no en contraposición evidente hacia lo no japonés, sino buscando recuperar lo que se pregonaba como tradicionalmente nipón.

Aunque el objetivo final de ambos ministerios y proyectos continuaba siendo una mejora económica a través del soft power derivado del atractivo de la cultura nacional, luego del terremoto, la primera meta fue reforzar la marca relativa a Japón, la cual destacaba las características de la sociedad tradicional. No mucho podía lograrse sin antes devolver la confianza en la calidad de los productos y el futuro del país a la sociedad japonesa y al resto del mundo, por lo cual la marca Japón, que hasta entonces había estado mucho más dedicada a atraer extranjeros, ahora tenía que ser combinada con una campaña interna para convencer a los japoneses de sus propias cualidades.

Los medios de comunicación nacionales, los productores culturales y las empresas comenzaron numerosos proyectos destinados a la revitalización de las zonas afectadas; todos 
hicieron uso del discurso sobre la solidaridad de los japoneses y el esfuerzo y amor que mostraban por su país. La campaña, que comenzó con la JTA, fue reforzada, como lo fueron las colaboraciones del grupo Arashi con diferentes medios de comunicación y corporaciones en producciones relacionadas con el fortalecimiento de la identidad y el orgullo nacionales.

Otro paso que dieron las élites fue a través de una campaña para obtener la sede de los Juegos Olímpicos del año 2020, la cual fue construida alrededor del siguiente mensaje: "Ahora, la fuerza de este sueño es crucial para Japón. Los Juegos Olímpicos y Paralímpicos nos darán un sueño. El sueño nos dará fuerza. La fuerza construirá el futuro. En este momento, para nosotros, esta fuerza es crucial. Para convertirnos en uno. Para fortalecernos. Comuniquemos al mundo la fuerza de Japón" ${ }^{47}$ Ésta habría de ser una estrategia de mediano plazo que invadiría los medios de comunicación y el panorama japoneses de fines de 2011 a fines de 2013, cuando la elección de la sede fuese anunciada. Durante ese tiempo, funcionaría paralelamente con el resto de los proyectos que llenarían la vida de los ciudadanos con el discurso de la "unidad japonesa", aligerado por ser insertado en los textos de las personalidades de cultura popular que ya poseían un fuerte poder de atracción.

Muchas otras figuras populares -atletas, cantantes, artistas plásticos, escritores- han estado siendo igualmente utilizadas como medios para la aplicación de las políticas de promoción cultural, aunque con diferentes enfoques discursivos. Por ejemplo, la contraparte femenil de Arashi -el grupo ídolo AKB48- ha gozado de amplio éxito en la industria musical nacional y, relativamente, en otros países asiáticos, por lo cual también ha sido llamado "nacional" por los medios de comunicación. Luego del desastre de 2011, ese grupo también ha estado siendo seguido en sus actividades de caridad en favor de las víctimas. En diciembre de 2013 fue presentado como representante de la cultura popular japonesa en el banquete ofrecido por el primer ministro Shinzō Abe a los líderes de los países

47 Tokyo 2020, “Tokyo 2020 Orinpikku Pararinpikku Shōchiinkai ga surōgan oyobi posutā wo hapyō”, en página web de Tokyo 2020, sección News, 29 de mayo de 2012. 
del sudeste asiático en la reunión de la Asociación de Naciones del Sudeste Asiático-Japón; ${ }^{48}$ sin embargo, la imagen mediática del grupo y sus integrantes se relaciona fuertemente con el fenómeno Cool Japan, al representar las posibilidades económicas de la promoción de la cultura popular nipona y evadir un discurso sobre la “japoneidad” de las integrantes, más allá de su orientación grupal y su estructura vertical.

\section{Conclusión}

Joseph Nye visitó Japón unos meses después del terremoto y expresó que quizá el desastre había sido un estímulo para el soft power de Japón. ${ }^{49}$ Ciertamente, ésa era la meta del gobierno, y aunque es muy pronto para saber los resultados de las políticas culturales sobre el poder de atracción de Japón en el mundo, dentro del país hay una clara recuperación del espíritu nacional, al menos así es desplegado en los medios de comunicación domésticos.

El proyecto de la marca Japón dentro del país se convertiría, desde 2011, en un discurso continuo de baja densidad sobre la identidad nacional que iría encontrando en personalidades de la cultura popular receptáculos y emisores: de exitosos artistas a talentosos atletas, muchas personalidades han sido envueltas en un discurso que alaba su atractivo y sus logros al mismo tiempo que destaca su papel como "representantes de los japoneses".

Nye ha sugerido que uno de los medios del gobierno para mantener el control, al mismo tiempo que aparenta ausencia en la diplomacia pública para la formación de soft power, es la utilización de agencias diversas que apliquen las medidas y lleven a cabo los proyectos; es eso lo que Japón ha estado haciendo. El discurso ha sido presentado en tan variadas fuentes - medios de comunicación privados y públicos, corporaciones, productores culturales, ministerios, comités no gubernamen-

\footnotetext{
${ }^{48}$ Sankei Digital, "AKB mo! Nichi-ASEAN bansankai de J-Pop hatsu raibu”, Sanpo. com, 15 de diciembre de 2013. de 2011.

${ }^{49}$ Joseph S. Nye, “A Reviving Japan?”, Fareed Zakaria GPS, 15 de noviembre
} 
tales, etcétera- que para el ciudadano común se vuelve difícil reconocer algún tipo de movimiento ideológico promovido por el gobierno. Justo cuando la estrategia de la ola coreana, obviamente gubernamental y, tal vez, imperialista, estaba ganando fuerza en Japón, conquistando altas cuotas de mercado en diferentes áreas culturales, los proyectos de Cool Japan y Japan Endless Discovery fueron formulados con un trasfondo discursivo moderado; sin embargo, el terremoto había creado la oportunidad perfecta para un proyecto y una campaña más extensa, aunque igualmente sutil, para reforzar la marca Japón, lo cual en el interior del país significaba fortalecer la identidad nacional.

Puede argumentarse que los japoneses han estado siendo expuestos desde entonces a constantes recordatorios sobre cómo debe ser un ciudadano japonés. En todos lados, el carácter nacional relacionado con la orientación al grupo, el respeto a la jerarquía vertical, el orgullo por la pertenencia a la sociedad japonesa y la recurrente diferenciación de lo japonés respecto de todo lo demás, comenzó a ser representado en un nuevo y atractivo empaque que por su atracción mundana y aparente falta de implicaciones ideológicas profundas tiene el potencial de facilitar la recepción del mensaje.

Dirección institucional de la autora:

Centro Universitario de Ciencias Sociales y Humanidades

Universidad de Guadalajara

Guanajuato 1045

Col. Alcalde Barranquitas

44260, Guadalajara, Jal.

yunueny@yahoo.com

\section{Bibliografía}

Arashi, Nippon no Arashi Pokettoban, Tokio, M.Co., 2011.

Befu, Harumi, Hegemony of Homogeneity. An Anthropological Analysis of Nihonjinron, Melbourne, Trans Pacific Press, 2001.

Cabinet Office Government of Japan, "Monthly Economic Report (December 2002)", en página web de Cabinet Office, datos al 
31 de diciembre de 2002. [www5.cao.go.jp/keizai3/getsureie/2002dec.html, consultado el 5 de junio de 2015.]

CHING, Leo, "Imaginings in the Empires of the Sun: Japanese Mass Culture in Asia", Boundary 2, vol. 21, núm. 1, 1994, pp. 198-219. ChuA, Beng H. y Koichi Iwabuchi (comps.), East Asian Pop Culture: Analyzing the Korean Wave, Hong Kong, Hong Kong University Press, 2008.

Cool Japan Advisory Council, Creating a New Japan. Tying together 'Culture and Industry' and 'Japan and the World', Tokio, Cool Japan Advisory Council, 12 de mayo de 2011. [www.meti.go.jp/ english/press/2011/pdf/0512_02b.pdf, consultado el 12 de mayo de 2013.]

Foster, Malcolm, "Japanese Mayor: Wartime Sex Slaves were Necessary”, Yahoo! Neres, 14 de mayo de 2013. [news.yahoo.com/ japanese-mayor-wartime-sex-slaves-were-necessary-042050746. html, consultado el 15 de mayo de 2013.]

IIDA, Yumiko, Rethinking Identity in Modern Japan: Nationalism as Aesthetics, Londres, Routledge, 2002.

IwaBUCHI, Koichi, Recentering Globalization. Popular Culture and Japanese Transnationalism, Londres, Duke University Press, 2002. Japan Airlines, “Tokubetsutosōki 'Jal Arashi JET' gashūkō”, comunicado de prensa en la página web de Japan Airlines, 9 de septiembre de 2010. [press.jal.co.jp/ja/release/201009/001620.html, consultado el 15 de mayo de 2013.]

Japan External Trade Organization, "Cool” Japan's Economy Warms Up, Tokio, JETro, 2005.

Kankō Keizai Shimbun, "Hōnichi kankō PR ni Arashi kiyō", en página web de Kankō Keizai Shimbun, sección Kankō gyōsei, 17 de abril de 2010. [www.kankokeizai.com/backnumber/10/04 17/ kanko_gyosei.html, consultado el 15 de mayo de 2013.]

Kankōchō, “Arashi x Kankōchō 'Kankō Rikoku Navigator' to shite Arashi wo kiyō”, en página web de Kankōchō, sección Hōdō Kaiken, 8 de abril de 2010. [www.mlit.go.jp/kankocho/en/ news01_000038.html, consultado el 15 de mayo de 2013.]

Kankōchō, "Kankō Promotion in Haneda Kūkō no Jisshidantaiga Kettei!”, en página web de Kankōchō, sección Hōdō Kaiken, 22 de abril de 2010. [www.mlit.go.jp/kankocho/news05_000059. html, consultado el 15 de mayo de 2013.]

Kankōchō, "Kankō Rikkoku Kyōiku ni shisuru tosho no sōfu to gakkō ni okeru sono katsuyō ni tsuite", en página web de Kokudokōtsūshō, 1 de septiembre de 2010. [www.mlit.go.jp/common/000124160.pdf, consultado el 15 de mayo de 2013.] 
Keizai Sangyōshō, "Cool Japan Shitsu no Setchi ni tsuite”, Web Archiving Project, 8 de junio de 2010. [warp.da.ndl.go.jp/info :ndljp/pid/8422823/www.meti.go.jp/press/20100608001/ 20100608001.html, consultado el 3 de junio de 2015.]

Keizai Sangyōshō, "Kontentsu Sangyō no kokusai tenkai ni mukete. Sekai he hasshin, Nippon burando", en página web de Keizai Sangyōshō, sección Seisaku, julio de 2003. [www.meti.go.jp/policy/ mono_info_service/contents/downloadfiles/kusaisenryakuken/ dai3kai/sank $\bar{k}$ osiryo.pdf, consultado el 15 de mayo de 2013.]

Keizai Sangyōshō, "Kore made Waga Kuni Kontentsu Sangyō no Kokusai tenkai ni muketa torigumi”, en página web de Keizai Sangyōshō, sección Bunka Shingikai, 21 de julio de 2004. [www. mext.go.jp/b_menu/shingi/bunka/gijiroku/019/04112601/003. pdf, consultad̄o el 15 de mayo de 2013.]

Korea Tourism Organization, "Korea, Monthly Statistics on Tourism”, en página web de Korea Tourism Organization, 2013. [kto. visitkorea.or.kr/eng/tourismStatics/keyFacts/KoreaMonthlyStatistics.kto, consultado el 21 de mayo de 2013.]

Korean Culture and Information Service, The Korean Wave: A New Pop Culture Phenomenon, Seúl, Ministry of Culture, Sports and Tourism, 2011.

Lam, Peng E., "Japan's Quest for 'Soft Power': Attraction and Limitation", East Asia, vol. 24, núm. 4, 2007, pp. 349-363.

Mandujano Salazar, Yunuen Ysela, "El mercado de idol varones en Japón (1999-2008): caracterización de la oferta a través del estudio de un caso representativo", tesis de maestría en Estudios de Asia y África, El Colegio de México, México, 2009.

Mcgray, Douglas, “Japan's Gross National Cool”, Foreign Policy, núm. 130, 2002, pp. 44-54.

Ministry of Economy, Trade and Industry, Contents Global Strategy. Final Report, Tokio, METI, julio de 2007. [www.meti.go.jp/ english/report/downloadfiles/g71015a02j.pdf, consultado el 15 de mayo de 2013.]

Ministry of Economy, Trade and Industry, Cool Japan Strategy, Tokio, METI, enero de 2012. [www.meti.go.jp/english/policy/ mono info service/creative industries/pdf/120116_01a.pdf, consultado el 15 de mayo de $\overline{2013 .]}$

Ministry of Economy, Trade and Industry, Economic Impact of the Great East Japan Earthquake and Current Status of Recovery, Tokio, METI, 16 de mayo de 2011. [www.meti.go.jp/english/ earthquake/recovery/pdf/20110516_impact.pdf, consultado el 12 de mayo de 2013.] 
Ministry of Economy, Trade and Industry, Report on the Content Industry's Growth Strategy, Tokio, METI, mayo de 2010. [www. meti.go.jp/english/press/data/20100514_01.html, consultado el 12 de mayo de 2013.]

Ministry of Economy, Trade and Industry, The New Growth Strategy Blueprint for Revitalizing Japan, Tokio, METI Cabinet Decision, 18 de junio de 2010. [www.meti.go.jp/english/policy/eco nomy/growth/report20100618.pdf, consultado el 15 de mayo de 2013.]

Nakagawa, Ulara, "Korea's Hallyu Boom?", The Diplomat, 27 de octubre de 2010. [thediplomat.com/new-emissary/2010/10/27/ koreas-hallyu-boo, consultado el 12 de mayo de 2013.]

National Police Agency of Japan, "Damage Situation and Police Countermeasures associated with 2011 Tohoku district off the Pacific Ocean Earthquake", datos al 11 de marzo de 2013, página web de National Police Agency of Japan. [www.npa.go.jp/archive/keibi/biki/index e.htm consultado el 17 de mayo de 2013.]

NYE, Joseph S., “A Reviving Japan?”, Fareed Zakaria GPS, 15 de noviembre de 2011. [globalpublicsquare.blogs.cnn.com/2011/11/15/ nye-a-reviving-japan, consultado el 3 de junio de 2015.]

Nye, Joseph S., Soft Power: The Means to Success in World Politics, Nueva York, Public Affairs, 2004.

Nye, Joseph S., "South Korea's Growing Soft Power", The Korea Times, 11 de noviembre de 2009. [www.koreatimes.co.kr/www/ news/opinon/2009/11/137 55438.html, consultado el 18 de mayo de 2013.]

NyE, Joseph S., The Benefits of Soft Power, Cambridge, Harvard Business School, 8 de febrero de 2004. [hbswk.hbs.edu/archive/4290. html, consultado el 17 de mayo de 2013.]

Ogawa, Reiko, "Re-imagining the Relationship between Japan and Korea: Popular Culture and Civic Engagement", en Henk Vinken, Yuko Nishimura, Brian White y M. Deguchi (coords.), Civil Engagement in Contemporary Japan. Established and Emerging Repertoires, Nueva York, Springer, 2010, pp. 189-202.

Oricon Style, "BoA, Besto-han ga 100 man mai wo toppa", página web de Oricon Style, sección News, 24 de mayo de 2005. [www. oricon.co.jp/news/4676/, consultado el 3 de junio de 2015.]

Oricon Style, "Eibekkusu, Tohoshinki no Nippon de no Katsudō Shien wo aratamete happyō", página web de Oricon Style, sección News, 6 de agosto de 2009. [www.oricon.co.jp/news/ 68236/full/, consultado el 3 de junio de 2015.]

Oricon Style, "Nenkan CD Arubamu rankingu", página web de Ori- 
con Style, sección Ranking, 31 de diciembre de 2008. [www. oricon.co.jp/rank/ja/y/2008/, consultado el 3 de junio de 2015.] Oricon Style, “Tohoshinki, Katsudō Kyūshi happyō", página web de Oricon Style, sección News, 4 de abril de 2010. [www.oricon. co.jp/news/74975/full/, consultado el 3 de junio de 2015.]

Poole, Robert M., "Only got 4Minutes to take the World. Girls make 'Candy Funk' Korea's New Export", The Japan Times Beta, 30 de abril de 2010. [www.japantimes.co.jp/culture/2010/04/30/ culture/only-got-4minutes-to-take-the-world, consultado el 18 de mayo de 2013.]

Recording Industry Association of Japan, "Nendo betsu Mirion Serā Ichiran", página web de Recording Industry Association of Japan, sección Kakurui Sōkei, 31 de diciembre de 2002. [www. riaj.or.jp/data/others/million_list/2002.html, consultado el 12 de mayo de 2013.]

Reuters, "South Korea's Pop-cultural exports Hallyu, yeah! A 'Korean wave' washes Warmly over Asia", The Economist, 25 de enero de 2010. [www.economist.com/node/15385735, consultado el 17 de mayo de 2013.]

Sankei Digital, “AKB mo! Nichi-ASEAN bansankai de J-Pop hatsu raibu", Sanpo.com, 15 de diciembre de 2013. [www.sanspo.com/ geino/print/20131215/akb13121505060000-c.html, consultado el 16 de diciembre de 2013.]

SHIM, Doobo, "Hybridity and the Rise of Korean Popular Culture in Asia”, Media, Culture E Society, vol. 28, núm. 1, 2005, pp. 25-44. The Chicago Council on Global Affairs, Soft Power in Asia: Results of a 2008 Multinational Survey of Public Opinion, Chicago, The Chicago Council on Global Affairs, 2009. [www.thechicagocouncil.org/UserFiles/File/POS Topline\%20Reports/Asia\%20 Soft $\% 20$ Power\%202008/Chicago\%20Council\%20Soft $\%$ 20Power\%20Report-\%20Final\%206-11-08.pdf, consultado el 19 de mayo de 2013.]

Tokyo 2020, “Tokyo 2020 Orinpikku Pararinpikku Shōchiinkai ga surōgan oyobi posutā wo hapyō”, en página web de Tokyo 2020, sección News, 29 de mayo de 2012. [www.tokyo2020.jp/ $\mathrm{jp} /$ news/index $\cdot \mathrm{php}$ ? $\operatorname{mode}=$ page\& $\mathrm{id}=174$, consultado el 3 de junio de 2015.]

Yasumoto, Seiko, "Japan and Korea as a Source of Media Cultural Capital”, en Duk-Soo Park (ed.), Global Korea: Old and Nerw: Proceedings of the Sixth Biennial Conference Korean Studies Association of Australasia, Sidney, The Korean Studies Association of Australia, 2009, pp. 311-321. [sydney.edu.au/arts/korean/ 
downloads/KSAA2009/Global_Korea_Proceedings_311-321 Yasumoto.pdf, consultado el 13 de mayo de 2013.]

Yoshimatsu, Hidetaka, "Identity, Policy Ideas, and Asian Diplomacy: Japan's Response to the Rise of China", International Area Studies Revierw, vol. 15, núm. 4, 2012, pp. 359-376.

Yoshino, Kosaku, Cultural Nationalism in Contemporary Japan: A

Sociological Enquiry, Londres, Routledge, 2005. 